\title{
TRICHINELLOSIS: NOW AND FOREVERMORE ?
}

\author{
MURRELL K.D.*
}

\section{Summary :}

The re-emergence of the zoonotic importance of trichinellosis reminds us that this parasite's unique biological features serve it well in helping it to persist in the face of 150 years of efforts to eliminate it from the food chain. Because of Trichinella's reemergence as an important public health risk, and the consequent stimulation of research, our knowledge of the parasite has grown, especially on the complexity of its biology and epidemiology. This overview will highlight the major features of this parasite's adaptive traits and the human factors that account for its reemergence in many regions, along with the actions of the International Trichinellosis Commission to address these issues. The attractiveness of Trichinella as a research subject for study of the parasitic lifestyle will also be emphasized, including areas for future research.

KEY WORDS : trichinellosis, Trichinella, emerging disease, zoonosis.

T Trichinellosis persists in confounding scientists and public health authorities who, after 150 years of control efforts, have expected it to recede to an incidental mention in text books. Prior to the 1970's, human trichinellosis from infected pork had declined markedly throughout the world, particularly in Europe and the United States. However, trichinellosis is again a serious public health threat in both the developed and the poorer regions (Murrell \& Pozio, 2000). The emergence, or re-emergence, of a parasite like Trichinella results from pertubation of the ecology of either the host, the parasite, or both, because zoonotic parasites exist within a continuum among animals, wild and domestic, and humans populations. Underlying causal factors which lead to changes include human encroachment and ecological manipulation, in the form of agricultural intensification and environmental alterations, translocations of animal populations, political turmoil, immigration, new patterns of food marketing and export, and changing economic conditions (Daszak et al., 2000). Important to this zoonosis, is the role played by the sylvatic Trichinella species, and the impact of human activities on their ecology (Pozio et al., 1996). The influence of

\footnotetext{
* Centre for Experimental Parasitology, Royal Veterinary and Agricultural University, Ridebanevej 3, 1870 Frederiksberg C, Denmark.
}

these forces on the epidemiology of trichinellosis are now being well-documented (see Murrell \& Pozio, 2000 for extensive review):

\section{SPILLOVER-SPILLBACK OF SYLVATIC AND DOMESTIC SPECIES OF TRICHINELLA}

]$_{\mathrm{r}}$ n the United States, from 1991-1996, nearly $40 \%$ of all cases of human trichinellosis were from eating game meat. In Illinois, for example transmission of T. spiralis from wild animals was responsible for infecting a domestic pig herd.

In Slovakia (1998), the primarily sylvatic T. britovi infected a dog which led to a human outbreak (336 cases). Bulgaria reported 2,335 human cases between 19931995, derived from both wild boars and domestic swine.

In 1994, an outbreak in Thailand (59 cases) was traced to infection of a feral domestic pig infected with the sylvatic species T. pseudospiralis.

The increase in human encroachment and ecological manipulation has been responsible for the introduction of T. spiralis to wild boars and bears in the United States and pastured domestic pigs in Croatia.

\section{CHANGING AGRICULTURAL AND FOOD MARKETING PRACTICES}

$\mathrm{P}$ rivatization of farms has been implicated as a major factor in the dramatic resurgence of trichinellosis in many of the East European countries during the 1990's: Romania, 16,712 cases; Russia, 3,152 cases; Lithuania, 1,240 cases; and Poland, 1,823 cases.

An increased use of animal protein in livestock feeding appears related to increased infection in cattle, sheep, pigs, and horses. The nearly 3,500 human cases of imported horse-meat trichinellosis in France and Italy over the last two decades, is likely the result of this practice. In China, records from 1964 to 1999 for 12 pro- 
vinces indicate there were 23,000 cases of trichinellosis, many which could be traced to the feeding of kitchen scraps to animals.

\section{TURMOIL FROM POLITICAL CHANGE, WAR AND IMMIGRATION}

T This is often the result of the erosion of the veterinary public health infrastructure, and a concomitant loss of experience and knowledge of trichinellosis, which, in turn, affects the ability to recognize the parasite, especially at slaughter, and causes complacency in inspectors. These are considered important factors in the recent resurgence of trichinellosis in Serbia (2,365 cases, 1995-1999) and Croatia (1,449 cases, 1994-1998). Immigration, often resulting from war and political events, can also play an important role; during the 1990's, several outbreaks of trichinellosis occurred among Southeast Asian refugees in the United States. Such people are vulnerable because of both a lack of knowledge of the zoonoses and their traditional food practices which, although perhaps safe in their country of origin, are now risky.

\section{IMPROVING OR CHANGING ECONOMIC CONDITIONS}

\begin{abstract}
surprising influence on the epidemiology of trichinellosis is the improving economic condi1 tions in many regions, where in Henan Province, China, for instance, rising incomes have led to an increased demand for meat. This has increased the risk of infection because of people's greater ability to buy more expensive, lightly "scalded", meat dumplings. These are believed to have been important sources for the 1,114 cases reported in that province from 1992-1993 (Wang et al., 1998).
\end{abstract}

\section{INTEGRATION AND GLOBALIZATION OF THE MARKETING SYSTEMS}

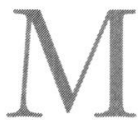
odern mass distribution of meat and meat products has had an impact on the epidemiology of trichinellosis. An excellent example of this is the recent (1998-1999) outbreak in the NorthrhineWestfalia region of Germany involving 52 cases (Rehmet et al., 1998). Rather than stemming from a local, single source, as is highly typical of trichinellosis outbreaks, this incident was the result of a diffuse exposure of people through a chain of markets spread over 10 cities and districts. The investigation of the out- break revealed that a shipment of meat, consolidated from nine abattoirs across Germany, Belgium and the Netherlands, was distributed from a central station to a chain of supermarkets which served about two million people. Investigators believe that hundreds of people throughout the region were exposed, although only $2 \%$ of case controls exhibited symptoms. This impact of modern, mass marketing systems on the trichinellosis paradigm may be increasingly felt worldwide.

\section{RESPONSE BY THE INTERNATIONAL TRICHINELLOSIS COMMISSION}

T $\mathrm{n}$ response to the re-emergence of trichinellosis and its shifting epidemiological features, the International Commission on Trichinellosis (ICT) has taken a number of actions to increase awareness of these changes and to provide access of the most up-to-date epidemiological control approaches for public health authorities, researchers, and the public:

1. Established the International Trichinella Reference Centre in Rome, Italy, to provide a source for identification of species and genotypes, and to provide typed isolates to the research community.

2. Established an ICT web site to provide information on trichinellosis and guidelines on detection and control of the zoonoses, timely reports on outbreaks and country prevalence data, and a directory of experts who can be called upon for consultation and assistance (http://www.med.unipi.it/ict/welcome.htm)

3. ICT has published guidelines for the veterinary public health community:

- Recommendations on Methods for the Control of Trichinella in Domestic and Wild Animals Intended for Human Consumption. 1999.

- Standardization of Immunodiagnostic methods (in preparation).

4. ICT convenes a Conference every four years to bring the research community together to exchange information and to debate issues. The proceedings of this Conference are published.

5. Provides, to the extent possible, speakers and representatives to other, related, conferences and meetings; this permits the transfer of up-to-date information and, in exchange, increases input to ICT on concerns and needs of other groups.

\section{FUTURE RESEARCH OPPORTUNITIES}

n these activities, it is the aim of ICT to assist the world-wide effort to control trichinellosis and to advance the efforts of the scientific community in 
understanding this resilient parasitic zoonosis. For researchers, Trichinella also presents a parasite model with many interesting features, some of which are common to other parasites, and others that are unique. Because of its relative ease of laboratory maintenance and manipulation, Trichinella offers scientists excellent opportunities to investigate basic issues in parasitology such as population genetics, host-parasite compatibility (and incompatibility), especially the immune response and the parasites' mechanism for coping with it, basic sensory biology questions such as host site and mate finding, and now, the functional genomics of a 200 parasitic nematode. The understanding of the unique ability of many Trichinella species to induce a muscle nurse cell for their larval "home" presents a difficult challenge, but one with a potentially great payoff. Of great interest also is the basis for the wide temperature tolerance of Trichinella, and its importance as an adaptive trait. These scientific questions, along with many others, ensure that Trichinella will be an object of attention well into the future. As a zoonosis, however, its future is more problematical, and depends on our ability to confront its varied and plastic epidemiology. Given its great persistence, in spite of a century and a half of control efforts, it is not unreasonable to expect that it will still be an important public health concern for some time to come.

\section{REFERENCES}

DaszaK P., Cunningham A.A. \& Hyatt A.D. Emerging infectious diseases of wildlife - threats to biodiversity and human health. Science, 2000, 287, 631-634.

Murrell K.D. \& Pozio E. Trichinellosis: The zoonoses that won't go quietly. International Journal of Parasitology, 2000. In Press.

Pozio E., la Rosa G., Serrano F.J., Barrat J. \& Rossi L. Environmental and human influence on the ecology of Trichinella spiralis and Trichinella britovi in Western Europe. Parasitology, 1996, 113, 527-533.

Rehmet S., Sinn G., Rostad O., Petersen L., Ammon A. \& LESSER D. Two outbreaks of trichinellosis in the state of Northrhine-Westfalia, Germany, 1998. Eurosurveillance, 1999, 4, 78-81.

WANG Z., LI H., Wu L. \& MaO F. Some observations on trichinellosis in China. Helminthologia, 1998, 35, 27-29. 